Council has decided upon a substantial increase in the rate of subscription for the processing sections of the industry.

The report refers to two circumstances which may delay the development by a research association of new processes-'teething' troubles accompanying their translation to commercial production, and requiring a willingness on the part of the industry to experiment, and the smaller incentive to bear the brunt of these troubles when results must be common property than when the knowledge gained is the exclusive property of a private firm.

Comment is again mainly devoted to the development of the processes, referred to in last year's report, for rendering wool 'unshrinkable' and for producing a permanent bleach.

The loss of 'handle' on chlorination is largely restored by 'fixanol'-this suggestion emanated from the Textile Chemistry Research Department of the University of Leeds-and it is now reported that substances of this type, which unite with wool substance, form a chemical link between the fibre and rubber latex, and a patented process has been evolved for rubberizing yarns to give water-repellent, moth-proof, and wear-resistant properties, and make available low-twist yarns of good strength.

Stress is laid on the importance of accurate measurement of fibre diameter as a fundamental necessity "for any progress to be made in the understanding of the manufacturing performance of wool", and "for the farmer to have reliable numerical data on which to base his breeding policy".

It is maintained that the fear expressed in some quarters that measurement of fineness in wool tops may become a bugbear in commercial dealings, could only be realized if it were used as a measure of quality, with the rather ambiguous comment that the latter is "a development which it is within the hands of the Trade alone to prevent".

Statistical analysis has also been applied to the variability of woollen card slubbing with the view of reducing uneconomic margins of tolerance.

Other subjects referred to as having received attention are the examination of proposed alternatives to olive oil for combing, of new detergents for wool scouring, and of the effect of various dyeing processes on the spinning power and handle of wool. An increased demand on the part of members for the investigation of special problems is also reported.

Thus it is evident that the Association is energetic. ally pursuing investigations on the technical and statistical sides, which may disarm any criticism of the restricted output of publications in scientific journals. Readers appreciating the functions of organized research in industry will, perhaps, feel more confident than the Director of Research that the non-participating section will diminish, but this will follow less from the reproof he administers than from a conviction borme of a fuller demonstration that it is missing benefits by standing aside.

\title{
Rothamsted Experimental Station
}

$\mathrm{T}$ HE form of the Rothamsted Report* for 1936 differs from those of former years in that a number of investigations which have extended over a period of years have been selected for detailed discussion, thus summarizing the results up to date. This type of annual report has an undoubted advantage in presenting the results of agricultural research, where a number of variable factors, such as seasonal effect, enter, tending to give uneven progress towards final conclusions; the results of one year may not give a representative picture of the work in hand. Though the work at Rothamsted is mostly of a fundamental type, the practical needs of the farming industry are kept continually in mind, the research programme being under constant scrutiny so as to follow up immediately those results likely to have a practical bearing. With long-period research, such as that embracing some of the field experiments which have been in progress for half a century, the need for such a policy is apparent, and it probably explains much of Rothamsted's secret of interesting both the research worker and the farmer.

The results of the various investigations on grassland problems come at a time when pasture management is a subject of topical interest and, for that reason, occupy most of this note; it may be mentioned that the recent International Grassland Congress visited Rothamsted in order to examine the Park grass plots. The Land Fertility Scheme, again, lends interest to the trials on the effects of manures

* Rothamsted Experimental Station; Lawes Agricultural Trust. Report for 1936. Pp. 294. (Harpenden: Rothamsted Experimental Station, 1937.) $2 s, 6 d$. on the botanical composition and yield of pastures. Attention is directed to the difficulties of drawing correct conclusions on the variations in the proportions of individual species as the result of manuring, because a decrease in one species may not, for example, be due to the direct action of the fertilizer, but to its being suppressed by an increase in another. Thus, the well-known effect of sulphate of ammonia in causing a decrease in the proportion of legumes in a mixed sward that is not closely grazed is due to their suppression by the greater growth of grasses resulting from this manure. It is interesting to note that the effect of lime has been most marked on the liberally manured plots, the plots standing out even in winter. Again, liming helped the sward to stand extremes of climate, heavy frost and drought having killed the herbage on the unlimed plots treated with sulphate of ammonia and mineral manures, while the grass on the limed plots was not affected. In the experiments with phosphatic manures, it has been observed that, by analysing the herbage and getting the figures for the percentage recovery of added phos. phate, it has become much easier to interpret the results of the trials than by merely observing yields of hay. This is the sort of information that should be kept in mind when the time arrives for assessing the success or otherwise of the Land Fertility Scheme.

The effect of the composition of the original seeds mixture sown when laying down a field to grass has been studied in a ley put down eight years previously. Research of this type has established the fact that, under most conditions, there is no particular advantage in sowing a large number of species, since, 
in a few years, these become reduced to a few, such as perennial ryegrass, wild white clover, etc.; exceptions to this sometimes come to light, such as when Percival observed that, in the Thames Valley, all the species of plants sown were still found after nineteen years. In the ley studied at Rothamsted, the ryegrass, cocksfoot, timothy, rough-stalked meadow grass and wild white clover formed the overwhelming bulk of the herbage after eight years. It is interesting to contrast some features of these results with those found by Alun Roberts at a number of centres in Wales, where the rainfall is higher, and where there is hard winter grazing by sheep. At Rothamsted, cocksfoot, and particularly timothy, survived much better than at the Welsh centres. Again, in the west, Italian ryegrass had completely disappeared at every centre in three years, while at Rothamsted this variety proved unexpectedly persistent, contributing largely after eight years; it must be assumed that this persistence was due to self-seeding. The Rothamsted experiments are important for large tracts in the drier parts of Fingland, where economic conditions have forced many to put down land to grass.

The experiments on the composition of ryegrass are of particular interest in view of the position regarding the various methods of grass conservation. The high proportion of fructosan, which is soluble in cold water, found in spring grass when the panicle emerges, and the decrease in this substance on further maturity, indicates that research in this direction may throw important light on such questions as losses in conserving young and more mature grass by various methods, and the relative values at different times of the year of pasture grass having similar chemical composition when expressed by the conventional method.

Experiments on the relation of cultivation to crop yield have been in progress since 1926, these being concerned with a study of the effects of the standard operations, and with a comparison of standard methods with rotary cultivation. There is a considerable body of evidence from other countries that yields are not increased either by extra or deeper cultiva. tion above a certain minimum well below what British farmers would accept, and eleven years experiments on heavy soil at Rothamsted and on light soil at Woburn tend to confirm this. Rotary cultivation, which produces a tilth in one operation, has given no harmful results when carried out on the same land year after year, provided that-for certain cropsit is done sufficiently deeply.

Other sections of the report, such as those dealing with the work of the Fermentation Department and of the Departments of Fungicides and Insecticides, and also of Entomology, are equally important because of the amount of valuable information contained in them.

\section{Display and Reference Exhibits in Museums}

\section{By Samuel G. Gordon, Department of Mineralogy, Academy of Natural Sciences of Philadelphia}

$\mathrm{T}$ HE new mineral gallery of the Academy of Natural Sciences of Philadelphia contains seven sections devoted to educational exhibits, the William S. Vaux Collection, Pennsylvania minerals, the fluorescent minerals, meteorites, gem stones, and special exhibits (radioactivity, new accessions, loan collections, etc.)

Frameless cases, virtually glass envelopes (described in the Museums Journal, November 1936) were designed in which the plate-glass is supported by a minimum of metal. Such construction was found possible in large wall cases, table cases, floor cases and pedestals, with the result that visitors are less 'case-conscious'. The educational exhibits (What is Geology ? What is a Mineral ? What is a Crystal ? The Interior of the Earth, etc.) are in wall cases lined with black suède-like paper which gives the incisiveness of a blackboard sketch. The labels, a tersely written sequence, are combined with the illustrative material (rigidly selected specimens, charts, maps, transparencies, models, instruments, etc.) in a layout in which lines, designs, colour, and other symbolic devices are used to develop a logical continuity. All other lines, arbitrary designs, meaningless colour, coarse textures, hardware, supporting accessories, ornamentation and distracting effects are avoided.

Less than 10 per cent of the minerals of the Academy collections are shown in the systematic series, about half in wall cases, and the rest in high table cases. Care was taken that each individual specimen, shown against black velveteen, was set up to the best advantage (four specimens took two hours apiece for this operation). Supporting means (mostly glass tripods) are unobtrusive. The green colour of glass shelves was found to be due to total reflection (within the plates) of the back edges; the colour was eliminated by painting the back edges black. Labels were printed on plastocele (cellulose acetate) with a lino-scribe, a device which uses printers' type and cuts. There is also an index with cross references to the minerals. Lighting (outside the cases) is concealed, and unobtrusive valances were used at strategic points in the wall cases to eliminate reflections.

The fluorescence exhibit (the first in America, following soon after that in the British Museum (Natural History)) is at the turning-point of the gallery. When reopened, it will be set in operation by the visitor passing a pair of photo-electric cells, and the automatic cycle (electric lights, ultra-violet lamps, darkness) will be synchronized with a fourminute record explanatory of the phenomena.

The focal point of the next section is another educa. tional layout: "What are meteorites?" Elaborate series of cut gemstones, jades, birth-stones, ormamental stones are shown in the succeeding bay. The last section includes an exhibit of radioactivity, in which the story of its discovery precedes a demonstration using an ionization chamber connected with a circuit terminating in a neon lamp which flashes as gamma radiation enters the chamber. 